\title{
The Influence of iPads on Course Performance and Student Perceptions of Learning in Human Anatomy
}

\author{
Lesley M. Scibora, DC, PhD \\ University of St. Thomas \\ l.scibora@stthomas.edu \\ Timothy Mead, PhD \\ University of St. Thomas \\ Mead3373@stthomas.edu \\ Claire Larson, MSN, RN \\ Marquette University \\ Claire.larson@marquette.edu
}

\begin{abstract}
The influence of iPad compared to computer-based active and collaborative learning activities on academic performance, along with student attitudes toward technology, engagement, and perceived learning were examined between two one-semester undergraduate-level Human Anatomy classes. Student attitudes and perceived learning were assessed using pre- and post-semester surveys between two simultaneous classes: iPad-integrated $(n=24)$ and no-iPad $(n=21)$. No-iPad users reported higher attainment of course objectives (human anatomy factual knowledge, principles and theories, and application of material) than iPad users. IPad users also reported lower levels of course engagement following fifteen weeks of usage whereas no-iPad users reported higher levels of engagement. Both groups showed similar learning gains based on test scores, and final grades. This article explores potential explanations for discrepancies with some previous research by highlighting the importance of consistent instructional methods, regardless of media, in undergraduate education.
\end{abstract}

Keywords: iPad, anatomy education, instructional methods, undergraduate education, technology in education, student perception

The iPad has been described as a potential educational 'game changer' (Geist, 2011; BrownMartin, 2010) and has been increasingly infused into higher education classrooms, including science, technology, engineering and math (STEM), and social science courses (Hwang \& Wu, 2014). Tablet ownership (including the iPad) among undergraduate students increased from $16 \%$ to $47 \%$ from 2013 to 2014 and nearly one-third of students report actively engaging with tablet technology in the classroom (Grajek, 2011). The Apple App Store cites over 80,000 educationfocused applications (i.e., apps) available for the iPad (Apple Inc, n.d.) that range from information gathering to collaborative content creation apps. The iPad is an instructional medium that offers potential affordances over laptop or desktop computers and traditional lecture-based, no-technology environments to improve student engagement, motivation, and learning (Cochrane, Narayan, \& Oldfield, 2013). Yet, there is little research examining the effectiveness of the iPad as a medium to enhance learning outcomes in undergraduate education, particularly in STEM courses (Hwang \& Wu, 2014). 
Recent reviews suggest there is significant interest in higher education in using tablets (including the iPad) and other mobile devices to promote learning (Cochrane, Narayana \& Oldfield 2014; Hwang \& Wu, 2014; Nguyen, Barton \& Nguyen, 2015). The premise of this interest appears to be based on the iPad-mediated affordances for student learning that include portability and applications focusing on knowledge acquisition, data collection, information storage and retrieval, real world models, and social connectivity and collaboration (Ferdousi \& Bari, 2015; Patten, Sanchez \& Tangney, 2006). IPads and computers offer media-based affordances over no-technology instruction media (i.e., textbooks), such as animation, simulation, and the ability for instructors and students to connect and collaborate outside of the classroom environment. Several lines of evidence suggest that use of iPad apps for learning increase student engagement with course material (Little, 2011) and increase student-to-student (Weider, 2011) and student-to-faculty (Goral, 2011) collaborations, organization skills (Gabel, Jakubek, McCarthy, Graham \& Wang, 2011), and creativity and critical thinking skills (Goral, 2011).

Finding that student engagement and motivation for learning is positively associated with the iPad, previous exploratory studies have primarily focused on instructor and student perceptions of the device (Nguyen, Barton \& Nguyen, 2015). For example, the iPad enhanced engagement in an undergraduate anatomy dissection laboratory by keeping students more on task and less likely to seek instructor assistance (Mayfield, Ohara, \& O'Sullivan, 2013). In another study, students reported positive experiences using the iPad in paperless chemistry laboratories (Hesser \& Schwartz, 2013). While pathways for achieving learning, motivation and engagement are important, they are qualitatively different from objectively measured learning (i.e., course performance). The iPad may enrich the learning experience (Angst, 2010; Handy \& Suter, 2011), but data regarding the impact of iPad use on learning outcomes remains inconclusive (Nguyen, Barton \& Ngyuen, 2015; Hwang \& Wu, 2014). Studies involving undergraduate STEM classroom or laboratory settings have observed no statistically significant effect on student course performance (George, Dumenco, Dollase, et al., 2013; George, Dumenco, Doyle, \& Dollase, 2013; Mayfield et al., 2013; Pickering, 2015). For example, mean exam scores did not differ between iPad and no-iPad remedial course groups in a pilot study among second-year premedical students (George, Dumenco, Dollase, et al., 2013). And, there was equivalent improvement in pre-to-posttest quiz scores, with no difference in posttest quiz scores, between introductory biology laboratory sections that relied on iPad technology and control laboratory sections (Pryor \& Bauer, 2008).

Differences in instructional methods, students' prior knowledge, iPad familiarity, technical challenges, and small sample sizes are important factors that may have confounded the results. However, these results are consistent with research which does not support a causal link between media type and student learning outcomes when different instructional media are compared (Clark, 2001), suggesting that there is a need to conduct well-designed studies that examine the iPad across different instructional mediums while controlling for confounders.

Cochrane, Narayan and Oldfield (2013) suggest inconclusive learning outcomes may be the result of failing to capitalize on the unique capabilities of the iPad to transform pedagogical strategies that foster student learning. This is evident in previous studies where the iPad was utilized only as a textbook or laboratory manual alternative, a note-taking device, or for searching the internet. By capitalizing on the collaborative, social, and real-world apps afforded by the iPad, instructional methods can be employed to improve student learning. However, using different instructional methods when delivering a lesson with an iPad compared to a desktop 
computer or without technology confounds the effect of the iPad in mediating learning. Others suggest that pedagogical methods cause learning, rather than the medium by which lessons are delivered to students, as posited by Clark’s method-not-media hypothesis (Clark, 2005; Sung \& Mayer, 2013).

There is robust evidence demonstrating the positive effect of employing active learning methods over traditional lecture-based instruction in the classroom on student engagement and improved course performance (Hake, 1998; Redish, Saul \& Steinberg, 1997; Prince, 2004). Active learning may be broadly operationalized as any instructional method that engages students meaningfully in activities during which they think about what they are doing and may be solitary or centered around student-to-student interactions (Bonewell, 1991). Importantly, many active learning methods can be employed consistently across different mediums. For example, a collaborative concept-mapping activity engages students in knowledge construction and interaction with classroom peers to develop higher order thinking skills important to learning, and can be utilized in a classroom without technology (e.g., on paper or poster board), and on a desktop computer or iPad (e.g., Mindmeister).

Anatomy courses have traditionally utilized lecture-based instructional methods (along with dissection laboratories) where students learn predominately by rote memorization with little practice in knowledge analysis, information synthesis, or real-world relevance (Johnson, Charchanti, \& Troupis, 2012). In recent decades, teaching anatomy has evolved to include a variety of technology-enhanced instructional strategies, including web-based learning, radiologic imaging, 3D software, audience-based response systems (i.e., clickers), and mobile platforms such as personal digital assistants, smartphones and tablet devices (including iPad) (Sugand, Abrahams, \& Khurana, 2010), to aid in student learning (Johnson et al., 2012). Tablet devices, including iPads, have been integrated into anatomy curriculum using a variety of approaches; paperless laboratories that use the iPad's e-text, anatomy dissector, note-taking, or screencasts to aid in drawing anatomical structures, but have not reported a causal link between the iPad and learning when controlling for instructional methods. Thus, the iPad may be an appropriate medium for students to learn human anatomy through iPad-integrated active and collaborative learning activities in the classroom setting that are aligned with course curriculum objectives. The purpose of the present study was to compare student course performance (i.e., student learning) and perceptions of engagement and learning as a result of active learning instructional methods delivered via the iPad or laptop computers in two concurrent undergraduate human anatomy course sections. It was hypothesized that iPad class participants would report more positive perceptions of learning without differences in course performance.

\section{Methods}

\section{Setting and Participants}

The study participants were undergraduate students enrolled in the human anatomy lecture and laboratory course during the fall of 2013 at the University of St. Thomas, St. Paul, MN. The human anatomy course consisted of two concurrent class sections taught by the same faculty member. The University of St. Thomas Information Technology Services (ITS) and the Center for Faculty Development purchased iPads for selected classroom use during the 2013-2014 academic year; these iPads were provided for the present study. The university's Institutional 
Review Board approved this study and all study participants provided informed, signed consent prior to collection of data.

\section{Study Design}

We conducted a quasi-experimental prospective study to assess the effect of iPad-integrated active and collaborative learning activities compared to complementary traditional notechnology and computer-based (i.e., laptop) learning activities on knowledge acquisition and student perceptions of course engagement, learning expectations and learning outcomes in the human anatomy course. One of two simultaneous class sections served as the iPad-integrated (iPad) classroom and the other section served as the control (no-iPad) classroom. The iPadintegrated anatomy class section was chosen based on availability of the iPads through ITS. Although iPads were not randomly assigned to each class, students in each class had equivalent pretest knowledge, based on score analysis of the 30-question general anatomy knowledge presemester assessment. All students were simultaneously enrolled in a corresponding laboratory section, but the iPads were only available for use during lecture sessions; there was one iPad available for each student.

Five iPad applications for the iPad-integrated course section were installed on the devices by ITS prior to the start of the semester. Applications developed for educational uses were selected to both teach specific anatomy content (e.g., muscular and skeletal systems) and engage students in classroom activities such as note-taking, concept-mapping, and clicker-type informal knowledge assessments. IPad applications included Mindmeister (Mindmeister Labs, Munich, Germany), eClicker (Silver Mana Software, LLC), Flashcards, iMuscle (3D4Medical, San Diego, CA), and Essential Skeleton (3D4Medical, San Diego, CA), and were all acquired through the Apple App store. To provide equivalent learning opportunities for the laptop/notechnology (no-iPad) class section, three of the five applications also had a complementary website accessible on a laptop computer.

The classroom activities utilizing the iPad apps included concept-mapping using Mindmeister, informal clicker-question assessments using eClicker, flashcard creation, and anatomical structure identification using the 3D interactive iMuscle and Essential Skeleton. As an example, students identified muscles and answered worksheet questions using the anatomyspecific apps. Since Essential Skeleton and iMuscle were available only on the iPad, complementary no-technology active learning activities and assignments for the no-iPad class included coloring and image labeling, and structure identification using plastic anatomical models, along with existing computer-based virtual anatomy software (AnatomyTV, Teton Data Systems, Jackson, WY).

Recommendations by Mang and Wardley (2012) were followed for successful implementation of iPad-based activities in classrooms, which are summarized as: (1) early decision of applications and feasibility for in-class use, (2) knowledge and mastery of the applications and device operating system by the instructor to effectively answer student's questions, (3) early introduction of the iPads with regular use to increase student's comfort and active engagement with the device, (4) proper instruction and acclimation by the students, and (5) technical support by the university's information technology department on a regular basis.

Of the 28 100-minute lecture sessions, iPad and equivalent laptop and no-technology activities were integrated into 11 (50\%) lectures; four class sessions were dedicated to exams. Other lectures remained similar between the class sections and included lecture, small group case 
study activities, hands-on activities with anatomical models, and audiovisual instructional modalities such as videos. For each iPad-integrated lecture session, iPads were distributed at the beginning of the class; students were introduced to the application, instructed on its use and given time to explore the application with classmates. At the end of each class session, iPads were collected from students and returned to IRT for use by another instructor on campus. Students in the no-iPad class were notified when class activities would require the use of laptops or desktop computers; all students in the class owned or had access to a laptop computer for these activities.

\section{Data Gathering and Analysis Methods}

Student performance on achieving learning outcomes was evaluated by administering a pretest and posttest anatomy knowledge test, which did not contribute to final course grades, to all students enrolled in the study (i.e., all students in the course) on the first and last day of class, respectively. The 30-question test was created with questions designed to test anatomy knowledge across the body systems, as they are covered in the class. Students' performance on learning outcomes was also assessed by examining final course grades, comprised of four exams and weekly assignments during the semester. The exams and weekly assignments were the same for both course sections.

Participants' current technology ownership, use, and general attitudes towards technology, along with student perceptions was evaluated across four learning indices: course performance expectations, perceived learning, achieving learning course objectives, and perceived engagement with course material via pre- and post-semester surveys in both the iPad and no-iPad groups. Pre- and post-semester surveys were administered to both groups on the first and last class day of the fall semester, respectively. Surveys were adapted from previous iPad research study instruments (Diemer, Fernandez \& Streepy, 2012; Pepperdine Community, 2011). The four indices assessing student learning perceptions were each comprised of between three and six 5-point Likert-scale questions (5 - strongly agree to 1 - strongly disagree) (see Table 2). The survey questions were tailored for no-iPad and the iPad groups so that the term 'technology' was used in the no-iPad class survey in place of 'iPad' for the iPad class group for each pertinent question. Pre- and post-semester surveys differed only in verb tense, reflecting the timing of survey administration at the beginning or the end of the semester.

\section{Results}

\section{Participant Characteristics}

Participant descriptive data is presented in Table 1. The mean age of participants was 20 years (range 19-22). Of the 45 participants, 38 of the students were from Minnesota and the rest were from a nearby border state. All were full-time students and all but two students were in their third year of college or later. Seventeen students lived in on-campus housing and all but one student had internet access at their residence. Twenty-seven of the students were majoring in Exercise Science, five in Health Promotion, two in Biology, five in Neuroscience, one in Business, and five were undecided. 


\section{Technology Ownership}

Participant technology ownership and usage data is presented in Table 1. Fifteen percent owned a desktop computer, 98\% owned a laptop computer, 98\% owned a smart phone, and 36\% owned some brand of tablet computer (iPad $=7$, Notebook $=2$, Kindle $=2$, Nook $=2$ ). Eighty-four percent used an Apple platform (iPhone) whereas 13\% used Google Android. Eighty-two percent responded that their mobile phone was the most important piece of technology whereas 16\% reported it was the laptop. Only one participant reported it was their tablet computer. All respondents stated that the laptop was the most important technology tool when thinking about the impact of technology on education and was their primary computing device. Table 1 provides frequency information for the iPad and no-iPad classes regarding their technology usage during and outside of class time.

Table 1. Frequency data (n) of participant demographics and technology usage

\begin{tabular}{|c|c|c|}
\hline & iPad & No-iPad \\
\hline \multicolumn{3}{|l|}{ Gender } \\
\hline Males & 8 & 7 \\
\hline Females & 16 & 14 \\
\hline \multicolumn{3}{|l|}{ Ethnicity } \\
\hline Asian & 2 & 2 \\
\hline African American & 0 & 1 \\
\hline Caucasian & 22 & 18 \\
\hline \multicolumn{3}{|l|}{ Technology usage for education } \\
\hline Daily & 22 & 17 \\
\hline $4-6$ times per week & 2 & 3 \\
\hline $1-3$ times per week & 0 & 1 \\
\hline \multicolumn{3}{|l|}{ Primary device for school } \\
\hline Laptop & 23 & 21 \\
\hline Mobile phone & 0 & 1 \\
\hline Other mobile computing device & 1 & 0 \\
\hline \multicolumn{3}{|l|}{ Technology use during class } \\
\hline Every class & 0 & 1 \\
\hline Most classes & 3 & 6 \\
\hline Some classes & 15 & 14 \\
\hline Never & 6 & 1 \\
\hline \multicolumn{3}{|l|}{ School computer lab usage } \\
\hline Daily & 0 & 2 \\
\hline $5-6$ times per week & 1 & 0 \\
\hline $3-4$ times per week & 3 & 2 \\
\hline $1-2$ times per week & 9 & 12 \\
\hline Never & 11 & 6 \\
\hline
\end{tabular}

Student Perception of Engagement and Learning Outcomes 
Table 2 provides a listing of the survey questions for each index used in the comparison of outcomes between the iPad class and the class that did not use iPads. To highlight the survey differences between the groups, question 1 of the Performance Expectations index states "Technology will encourage exploration of human anatomy topics" for the no-iPad group. This language difference was consistent in the no-iPad class surveys. With the exception of Feelings about Technology (question 3), question responses for all other indices were in a Likert scale format with the following options: 5 = strongly agree, 4 = agree, $3=$ neither agree nor disagree, 2 = disagree, and 1 = strongly disagree. Scores for each survey question were summed to obtain an index score that was then used in the analysis of within-group pre- and post-semester scores and between the iPad group and the no-iPad group. Reliability of the survey instrument was determined by calculating internal consistency (Cronbach's alpha) of the pretest survey, which was 0.94 .

Table 2. IPad group pre-semester survey across indices of general technology use and student perception of learning

\section{Feelings about Technology (FAT)}

1. Overall, technology makes my life easier.

2. I feel I accomplish more in my student life because of technology.

3. Given my use of all technologies at my disposal, on average I feel I am an expert (5), advanced (4), intermediate (3), basic (2), or non-technology user (1).

\section{Performance Expectations (PEX)}

1. The iPad will encourage exploration of human anatomy topics.

2. The iPad will provide functions/tools that are not possible with a traditional textbook.

3. The iPad lacks important functions/ tools that are available with traditional textbook.

4. I will learn more anatomy as a result of iPad.

5. Using the iPad will make anatomy more interesting.

6. I would learn more in any class by using the iPad.

\section{Perceived Learning (PLE)}

1. The iPad activities will help me apply course content to solve problems and think critically.

2. The iPad activities will help me to learn course content.

3. The iPad activities will help me connect ideas in new ways.

4. The iPad activities will help me participate in the course activity in ways that enhance my learning.

5. The iPad activities will help me develop confidence in the subject of human anatomy.

\section{Meet Course Objectives (MCO)}

1. Use of the iPad will help me to gain factual knowledge of human anatomy structure and function.

2. Use of the iPad will help me to learn fundamental principles, generalizations, or theories of anatomy. 
3. Use of the iPad will help me to learn to apply this course material.

\section{Perceived Engagement (PEN)}

1. IPad activities will motivate me to learn the course material more than not using iPad.

2. I will participate more in class during the iPad activities than during activities that did not use an iPad.

3. My attention to the task will be greater using the iPad.

4. The iPad will be more convenient compared to desktop or laptop.

5. It will be easier to work in a group using the iPad than in other group activities.

6. IPad activities will be an important supplement to this class.

In order to determine the impact of the iPad on learning outcomes, a repeated measures (pre-post semester surveys) analysis was performed. Index scores were created by adding scores on the survey items (see Table 2) under each index for the pre and post surveys. The repeated measures ANOVA then calculated the variability on each index score in order to determine statistical differences between the class using iPads and the no-iPad class. The statistical package SPSS, version 22 (Chicago, IL) was used in all data analyses. Table 3 presents the means and standard deviations for each pre- and post-semester index score for the iPad and no-iPad classes. Five students were missing either a pre- or post-semester survey so these students were not included in the data analysis. A 2 (Pre - Post) X 2 (iPad - no-iPad) within subject ANOVA was computed for each of the five indices. Table 4 lists the significant main effects of the indices from the 2 X 2 ANOVA. For MCO, a significant interaction was computed between pre/post and $\mathrm{iPad} /$ no-iPad usage, $\mathrm{F}(1,38)=4.3, p=.046$. For PEN, a significant interaction was computed between pre/post and iPad/no-iPad usage, $\mathrm{F}(1,37)=4.3, p=0.046)$. Both significant interactions are shown in Figure 1.

Table 3. Pre- and post-semester student perception of learning outcomes by group

$$
\text { iPad (n = 21) } \quad \text { No-iPad }(n=19)
$$

\begin{tabular}{|c|c|c|c|c|c|c|c|c|c|c|}
\hline & Pre & & Post & & $\begin{array}{l}\text { Pre- } \\
\text { Post }\end{array}$ & Pre & & Post & & $\begin{array}{l}\text { Pre- } \\
\text { Post }\end{array}$ \\
\hline Index & $\mathbf{M}$ & SD & $\mathbf{M}$ & SD & $\mathbf{M}$ & $\mathbf{M}$ & SD & $\mathbf{M}$ & SD & $\mathbf{M}$ \\
\hline FAT & 12.8 & 1.4 & 12.4 & 1.5 & 12.6 & 12.8 & 1.5 & 13.2 & 1.2 & 13.0 \\
\hline PEX & 22.3 & 2.5 & 21.9 & 2.7 & $22.1^{*}$ & 23.8 & 2.5 & 25.0 & 1.7 & $24.4^{*}$ \\
\hline PLE & 20.1 & 3.1 & 19.2 & 3.3 & $19.6^{*}$ & 21.1 & 2.3 & 22.1 & 2.1 & $21.6^{*}$ \\
\hline MCO & 11.9 & 2.2 & 11.7 & 1.6 & $11.8 *$ & 12.5 & 1.3 & 13.8 & 0.9 & $13.2^{*}$ \\
\hline PEN & 22.1 & 3.2 & 20.5 & 3.0 & $20.8 *$ & 18.4 & 3.3 & 19.7 & 2.5 & $19.1^{*}$ \\
\hline
\end{tabular}

Data are presented as mean (M) and standard deviation (SD). *Between-group differences (iPad vs. No-iPad) significant at $p<0.05$. 
Table 4. Main effects of student perception of learning indices between groups

\begin{tabular}{cccccccc}
\multicolumn{7}{c}{ iPad } & \multicolumn{2}{c}{ No-iPad } \\
Main & Index & M & SD & M & SD & F (df) & p-value \\
\hline Effects & PEX & 22.1 & 2.0 & 22.4 & 2.0 & $19.6(1,38)$ & $<0.001$ \\
& PLE & 19.6 & 3.0 & 21.6 & 2.2 & $8.6(1,37)$ & 0.006 \\
& MCO & 11.8 & 1.9 & 13.2 & 1.1 & $13.8(1,38)$ & 0.001 \\
& PEN & 21.3 & 3.7 & 19.1 & 2.8 & $8.0(1,37)$ & 0.008
\end{tabular}

Data are presented as mean (M) and standard deviation (SD).

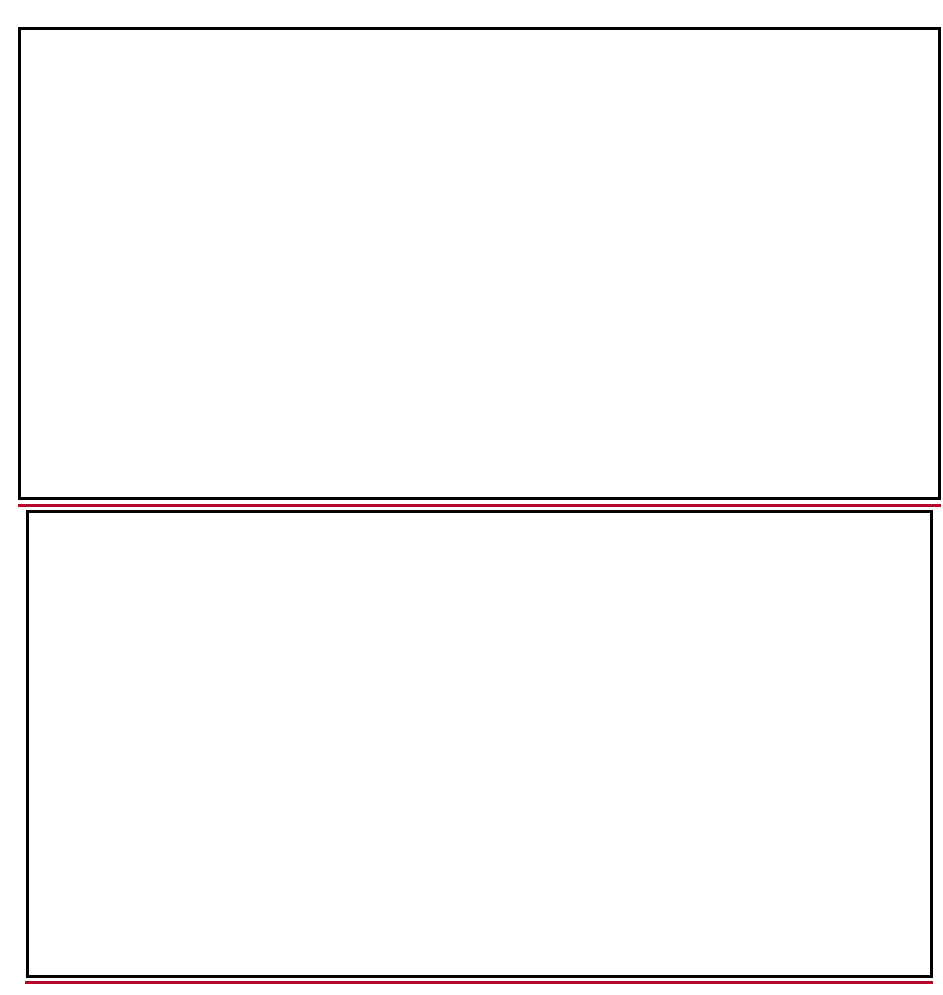

Figure 1. Significant group by time interactions on student perception of learning indices. Upper panel: Meeting Course Objectives (MCO) mean scores by group (iPad vs. no-iPad) assessed at pre- and post-semester time points. Interaction significant at $p=0.046$. Lower panel: Perceived Engagement (PEN) mean scores by group (iPad vs. no-iPad) assessed at pre- and postsemester time points. Interaction significant at $p=0.038$. For both panels: iPad (solid line) and no-iPad (dashed line).

An Analysis of Covariance (ANCOVA), with survey pre-scores as a covariate, was computed for each survey index in order to allow pre-score equivalence of the two classes. Presemester scores on the survey were not equivalent. They were higher for the no-iPad group in all Journal of Teaching and Learning with Technology, Vol. 7, No. 1, Spring 2018 jotlt.indiana.edu 
but one case. For the index MCO, a significant effect was found between the iPad and no-iPad classes, $\mathrm{F}(1,37)=22.2, p<.001$. For the index PEX, a significant effect was also found between the iPad and no-iPad classes, $\mathrm{F}(1,37)=17.5, p<.001$. The same result was found for the index PLE, $\mathrm{F}(1,37)=8.7, p=.006$. However, when pre-survey scores were controlled with ANCOVA, the index PEN was not different between the two classes, $\mathrm{F}(1,37)=.087, p=.77$ and the index FAT was different, $\mathrm{F}(1,37)=5.0, p=.032$.

\section{Student Course Performance}

An independent t-test comparison was made to compare final percent grades between the iPad class $(\mathrm{M}=87.1, \mathrm{SD}=7.3)$ and the no-iPad class $(\mathrm{M}=87.7, \mathrm{SD}=7.8), \mathrm{t}(43)=0.27, p=0.79$, revealing no difference between the classes on final course grades. A 30-item pretest/posttest general anatomy knowledge quiz was given the first day of class and the last day of class. A comparison of gain scores (posttest - pretest) revealed that the iPad $(\mathrm{M}=8.5)$ and no-iPad $(\mathrm{M}=$ 7.6) classes improved the same over the course of the term, $\mathrm{t}(40)=0.71, p=.55$.

\section{Discussion}

This is the first known study to examine both student learning and student perceptions of iPadintegrated learning activities in an undergraduate human anatomy course. This study compared the classroom use of active learning methods delivered via iPad to traditional no-technology and laptop media on measures of student course performance, along with student perceptions of course performance expectations, engagement, and learning human anatomy. Students in both groups reported similarly in their feelings toward technology. Importantly, results showed that students performed equally well on knowledge of course content and that students who did not use an iPad in classroom activities perceived their engagement with course material and learning to be greater that those students who used an iPad. Aspects of these findings are discussed below.

\section{Technology Ownership and Use}

The study results confirmed that participants report similar technology ownership and usage of those previously reported by Cassidy and colleagues (2014), where 96\% of 987 surveyed university students owned laptop computers. In the present study, laptop computer ownership was nearly unanimous (98\%) amongst the students and 36\% also owned a tablet computer (including the iPad). Similar to other reports, students all stated the laptop computer was their most important piece of technology for education, and their primary computing device. Further, both groups felt similarly about technology. When asked if technology made life easier, and when separately asked if technology allowed for greater personal accomplishments, both the iPad and no-iPad groups agreed (96\% and 90\%, respectively). Both groups perceived value in technology for daily living, but technology use in the higher education realm is rather different. We discuss below student perceptions of technology in the classroom setting.

\section{Student Perceptions of iPads and Technology on Learning}

Across each of the survey indices assessing student perceptions of iPads and technology on learning human anatomy, the results surprisingly show that the no-iPad group reported more 
favorable performance expectations, perceived learning and meeting overarching course objectives as a result of technology use in general, compared to perceptions of students using the iPad, specifically. Students who did not use the iPad agreed (averaged a '4' or better on the Likert scoring) that technology-based learning activities, in general, would enhance their ability to learn human anatomy content, apply the content to solve problems and think critically, connect ideas in new ways, and develop confidence in human anatomy knowledge. Further, students engaged in no-technology and laptop-based classroom learning activities reported significantly stronger agreement in learning content, class participation and attention to task, and effectively working with a group over the semester compared to students who used the iPads. Previous studies have shown mixed outcomes regarding student perception of the iPad's value in an educational setting, particularly compared to other learning platforms. Suggesting that the response to iPad-integrated classrooms is nearly evenly divided among students, 53\% and 42\% of undergraduate anatomy students in a study by George et al. (2013) felt that using the iPad aided in both learning anatomy and understanding the material during lecture, respectively. In another study, Diemer and colleagues (2012) showed higher levels of perceived learning among college students across a range of disciplines as a result of iPad-based active learning classroom activities. However, this result was correlated with higher comfort levels of in using various modes of mobile learning and not measured against other modalities of active learning. Given that nearly all students in the present study reported using the laptop as their primary computing device (Table 1) and reported no differences in their feelings about technology (Table 2), students not using the iPads may have felt more comfortable with technology they already used both inside and outside of class. While not measured, it is also possible that students in the iPad group may have been apprehensive or uncomfortable with less familiar technology. Even after instruction and practice with the devices prior to classroom learning activities student perceptions did not change over the semester.

Congruent with the hypothesis, perceived engagement was lower, albeit initially, in the class not using iPads (Table 3). However, a closer investigation reveals that the higher reported engagement of iPad users wears off over the course of the semester (Figure 1). By the end of the course, there was no difference in perceived engagement between the class sections. Interestingly, George et al. (2013) reported that $79 \%$ of pre-medical students initially agreed that "the iPad was a positive addition to the [anatomy] curriculum", but agreement declined to 49\% by the end of the semester, suggesting that iPad interest and novelty may be temporary. Focus group outcomes in that study also revealed that iPads might be better utilized in laboratory versus lectures settings (George et al., 2013); students reported note-taking and e-textbook challenges in the classroom. Supporting this notion, Mayfield et al. (2013) found that anatomy lab students assigned to dissection tables using iPad-based manuals spent significantly more time on task, were less likely to seek instructor assistance, and reported higher perceptions of meeting laboratory objectives compared to paper manual-based control students; concluding that iPads aided in learner engagement. While the iPads were not an effective means to increase student perceptions of course engagement, perceived learning, or meeting course objectives in the present study, general knowledge test and overall course performance was no different between course sections. 


\section{Course Performance}

Students report they approach learning anatomy through visualization, memorization, and understanding, and that each of these methods produces differing effects on knowledge retention (Pandey \& Zimitat, 2007). Students who engage in deep (i.e., understanding) methods of study, where the interrelationships between facts is understood and knowledge is structured, appear to have better knowledge processing and long-term recall compared to those students who rely on memorization, where facts may be disjointed and knowledge unstructured (Ward, 2011; Ward \& Walker, 2008). In the present study, active learning strategies were based on overarching course objectives and creating a student-centered collaborative learning environment that would assist students in integrating and applying course content to increase knowledge. The premise for adopting the iPad into higher education classrooms is that it seemingly provides unique affordances over computers and no-technology classroom environments by providing immediate feedback to students on content understanding, generating classroom discussions through polling or clicker-type applications, linking concepts, and sharing student generated content through mind-mapping applications (Cochrane, Narayan \& Oldfield, 2013). Using the Mindmeister application to create collaborative concept maps of articulations actively engaged students in generating content, visualizing and understanding the organization of relationships and differences between articulation type, structure and location. However, students in the no-iPad class also engaged in an equivalent activity using Mindmeister on laptop computers. Given the evidence demonstrating that active learning is positively associated with learning (Carini, Kuh, \& Klein, 2006; Prince, 2004), the equivalence in course performance between course sections supported our hypothesis.

In the present study, students who used the iPad for active learning activities during class performed the same as those students who engaged in no-technology or laptop-based class activities, as measured by final course grades. Moreover, pre- and posttest general anatomy test scores showed that students in both classes improved similarly in their knowledge of human anatomy. Correspondingly, George et al. (2013) found no differences in exam scores between iPad and no-iPad groups of second-year pre-medical students in a remediation course. Pryor and Bauer (2008) also showed equivalent improvement in pre-to-posttest quiz scores between iPadintegrated and control biology laboratory sections, attributing their non-significant outcomes to teaching style differences among faculty who instructed the lab sections. In this study, the same faculty member taught both course sections using equivalent instructional strategies, suggesting that instructional methods may be more effective in improving student learning than the medium by which the lesson is delivered (Clark, 2005). In contrast, Raney (2014) showed that undergraduate human anatomy students given personal iPads performed better than those who did not use iPads or were limited to iPad use in the laboratory, but that the effect of iPads on course performance was time dependent. That most previous investigations, including the present study, found no effect of iPad use on course performance may also be a result of educational setting (i.e., laboratory or lecture), or that the iPads were used in a variety of ways in each setting. Use of the iPad as a note-taking device in the classroom, for example, may not directly enhance content understanding in the same way as using an application to interact with course material in small groups, as was the case in the present study. Existing iPad-based applications designed for educational use were selected to increase student engagement and foster active learning. Others have developed novel programs and applications such as flashcards (Trelease, 2008) and screencasts (Pickering, 2015) - specific to the anatomy classroom - to 
improve knowledge acquisition. However, neither existing educational iPad applications nor unique applications significantly improved student course performance either compared to controls or previous students of the same course, even though students self-reported an increase in anatomy knowledge as a result of their use (Pickering, 2015). Both course sections in the present study engaged in active and collaborative learning, albeit using differing modalities. In this instance, perhaps there are not unique affordances of the iPad over computer or notechnology mediums when applied in the classroom setting compared to iPad use outside of the classroom.

For successful implementation of the iPads into the classroom, Mang and Wardley (2012) and others (Diemer, 2012; Pepperdine Community, 2011) state that students should be acclimated early to the device and use it regularly to increase comfort and active engagement. Lack of comfort or knowledge, along with technical difficulties in using the iPad may be the reason students in previous studies favored laptop over iPad use (Handy \& Suter, 2011). Students in the present study used the iPad in half of the semester class sessions and were given instruction and time to practice with the iPad and corresponding application prior to the learning activity, but did not have access to the device outside of class. As a mobile device, access outside of the classroom may lead to increased engagement with material and, in turn, increased knowledge retention, but of studies that provided students with iPads to use outside of the classroom, none reported how often the devices were used for learning anatomy. However, usage data from a recent study that examined the use of anatomy drawing screencasts during a medical school anatomy course found that $93 \%$ of students $(n=223)$ accessed the screencasts, with 5.4 downloads per students which increased prior to each practical examination (Pickering, 2015), which suggests that utilizing the mobile benefits of the iPad may increase students' regularity of use, comfort, and engagement with course material outside of class and improve knowledge.

Several factors should be considered when interpreting the results of this study. Since the iPads were simultaneously used by three other courses in the university during the fall semester, classroom iPad access was only granted during select available times. Moreover, the iPads were not used in all of the classroom meetings, or during the laboratory. Given limited time with the devices students may have lacked familiarity with the particular applications used during class time to allow for adequate engagement and learning. Moreover, the effects of iPads on learning may have been different if the students were able to use them outside of class. Although the selected iPad applications had a corresponding website that could be accessed outside of class on the student's laptop computer or other computer, students were not required to use them since the study objective was to examine the effect of the classroom use of the iPad compared to more traditional technology on learning. Correspondingly, students in the no-iPad classroom were also able to access the traditional technology learning activity websites and programs outside of class on their personal laptop. While activity usage outside of the classroom was not measured, it is possible that students' performance was disproportionately affected by increased learning outside of class time. Finally, the lack of differences in course performance between class sections may have been due to the small sample size in the present study. In a larger undergraduate human anatomy course, some of which exceed 100 students, differences in course performance and perceived learning outcomes may be elucidated or more pronounced. 


\section{Conclusions}

The interactive and visual aspects of the iPad, along with other tablet devices and smartphones, may provide numerous opportunities for students to gain anatomical knowledge. Results of this study showed that iPads stimulated interest among students but they did not produce better (or worse) academic performance nor did they increase positive attitudes about learning. However, iPads may be an additional medium that university educators can use to teach anatomy, particularly when utilized as part of an active learning classroom environment. Along with the present research, few studies have found distinct advantages in using the iPad as a platform for increasing students' anatomy knowledge, but confounding instructional methods and uses of the device (i.e. note-taking, aiding in dissection) may have precluded a clear understanding of whether the iPad is a useful learning medium. As these devices become more widely adopted by students for the anatomy classroom and laboratory, educators and researchers should investigate ways in which applications can be used and assessed both inside and outside of the classroom to deepen student engagement with course material. As students become more familiar with iPads for both personal and educational use, it will be important to assess whether greater knowledge gains are achieved when students require less acclimation with the tablet platform and spend more time understanding anatomy content. Finally, application developers should consider incorporating knowledge or skill assessment tools that could be included in future guidelines for successful iPad integration into the classroom.

\section{References}

Angst, C., and Malinowski, E. (2010). Findings from ereader project, phase 1: Use of iPads in MGT40700, project management (M. C. o. Business, Trans.) University of Notre Dame Working Paper Series (pp. 1-17): University of Notre Dame.

Apple Education. (n.d.). Retrieved August 15, 2017 from https://www.apple.com/education/apps-books-and-more/.

Bonewell, C.C. and Eison, J.J. (1991). Active learning: creating excitement in classroom. http:/www.ntif.com.htm/lib/bib.him.

Brown-martin, G. (2010). iPad - a game changer for learning? Learning without frontiers: Our blog. Retrieved on May 20, 2016, from http://www.learningwithoutfrontiers.com/blog/2010/11/23/ipad-a-game-changer-forlearning.html.

Carini, R.M., Kuh, J.D., and Klein, S.P. (2006). Student engagement and student learning: Testing the linkages. Research in Higher Educa, 47(1), 1-32. doi:10.1007/s11162-005-8150-9.

Cassidy, E.D., Coleemenares, A., Jones, G., Manolovitz, T., Shen, L., Vieria, S. (2014). Higher education and emerging technologies: Shifting trends in student usage. Journal Acad Librarian, 40, 124-133.

Clark, R. E. (2001). Learning with media. Greenwich, CT: Information Age Publishing. 
Clark, R. E. (2005). Five common but questionable principles of multimedia learning. In R. E. Mayer (Ed.), The Cambridge handbook of multimedia learning. New York: Cambride University Press.

Cochrane, T., Narayan, V., and Oldfield, J. (2013). iPadagogy: Appropriating the iPad within pedagogical contexts. Int J Mobile Learn Organisation, 7(1), 48-65.

Diemer, T.T., Fernandez, E., and Streepey, J.W. (2012). Student perceptions of classroom engagement and learning using iPads. Journal of Teaching and Learning with Technology, 1(2), 13-25.

Ferdousi B., and Bari J. (2015). Infusing mobile technology into undergraduate courses for effective learning. Procedia Soc Behav Sci, 176, 307-311.

Gabel, Laine, Jakubek, Dan, McCarthy, Graham, and Wang, Weina. (2011). Project iPad. Computers in Libraries, 31(7), 17-21.

Geist, E. (2011). The game changer: using iPads in college teacher education classes. College Student Journal, 45, 758-768.

George, P., Dumenco, L., Dollase, R., Taylor, J. S., Wald, H. S., and Reis, S. P. (2013). Introducing technology into medical education: two pilot studies. Patient Educ Couns, 93(3), 522-524. doi: 10.1016/j.pec.2013.04.018.

George, P., Dumenco, L., Doyle, R., and Dollase, R. (2013). Incorporating iPads into a preclinical curriculum: a pilot study. Med Teach, 35(3), 226-230. doi: 10.3109/0142159X.2012.735384.

Goral, T. (2011). Take II tablets. University Business, 46-49.

Grajek, S. (2011). The current state of college students and technology 2011. Paper presented at the 2011 EDUCAUSE Center for Analysis and Research Symposium, Chicago, IL. Presentation retrieved from http://www.educause.edu/ecar.

Hake, R.R. (1998). Interactive-engagement versus traditional methods: A six-thousand-student survey of mechanics test data for introductory physicis courses. American Journal of Physics, 66(64). doi: 10.1119/1.18809.

Handy, B. and Suter, T. (2011). IPad study released by Oklahoma State University. Oklahoma State University, Oklahoma City, OK. Retrieved November 12, 2015, from https://news.okstate.edu/articles/ipad-study-released-oklahoma-state-university.

Hesser, T.L., and Schwartz, P.M. (2013). iPads in the Science Laboratory: Experience in designing and implementing a paperless chemisty laboratory course. Journal of STEM Education, 14(2), 5-9. 
Hwang, G.J., and Wu, P.H. (2014). Applications, impacts and trends of mobile technologyenhanced learning: A review of 2008-2012 publications in selected SSCI journals. International Journal Mobile Learn Organisation, 8(2),83-95.

Johnson, E.O., Charchanti, A.V., and Troupis, T.G. (2012). Modernization of an anatomy class: From conceptualization to implementation. A case for integrated multimodal-multidisciplinary teaching. Anatomical Sciences Education, 5, 354-366. doi: 10.1002/ase.1296.

Little, G. (2011). Managing technology. Keeping moving: Smart phone and mobile technologies in the academic library. Journal of Academic Librarianship, 37(3), 267-269.

Mang, C.F. and Wardley, L.J. (2012). Effective adoption of tablets in post-secondary education: Recommendations based on a trial of iPads in university classes. Journal of Information Technology Education: Innovations in Practice, 11, 301-317.

Mayfield, C.H., Ohara, P.T., and O'Sullivan, P.S. (2013). Perceptions of a mobile technology on learning strategies in the anatomy laboratory. Anatomical Science Education, 6(2), 81-89. doi: 10.1002/ase.1307.

Nguyen, L., Barton, S.M., and Nguyen, L.T. (2015). iPads in higher education-Hype and hope. British Journal of Education and Technology, 46, 190-203.

Pandey, P., and Zimitat, C. (2007). Medical students' learning of anatomy: memorisation, understanding and visualisation. Medical Education, 41(1), 7-14. doi: 10.1111/j.13652929.2006.02643.x.

Patten, Sanchez and Tangney (2006). Designing collaborative, constructionist and contextual applications for handheld devices. Computers \& Education, 46, 294-308. doi: 10.1016/j.compedu.2005.11.011.

Pepperdine Community. (2011). Pepperdine University, Malibu, CA. Retrieved August 20, 2013, from: http://community.pepperdine.edu/it/tools/ipad/research/results.htm.

Pickering, J.D. (2015). Anatomy drawing screencasts: enabling flexible learning for medical students. Anatomical Science Education, 8(3), 249-257. doi: 10.1002/ase.1480.

Prince, M. (2004). Does active learning work? A review of the research. Journal of Engineering Education, 93(3), 223-231.

Pryor, G. and Bauer, V. (2008). Building a better biology lab? Testing tablet PC technology in a core laboratory course. Journal of College Science Teaching (November/December), 44-48.

Redish, E., Saul, J. and Steinberg, R. (1997). On the effectiveness of active-engagement in microcomputer-based laboratories. American Journal of Physics, 65(1), 45. 
Raney, M. (2014). Dose- and time-dependent benefits of iPad technology in an undergraduate human anatomy course. The Journal of the Federation of American Societies for Experimental Biology, 28(1), Supplement 725-728.

Sugand, K., Abrahams, P., and Khurana, A. (2010). The anatomy of anatomy: a review for its modernization. Anatomical Science Education, 3(2), 83-93. doi: 10.1002/ase.139.

Sung, E. and Mayer, R.E. (2013). Online multimedia learning with mobile devices and desktop computers: an experimental test of Clark's methods-not-media hypothesis. Computers in Human Behavior, 29(3), 639-647. doi: 10.1016./j.chb.2012.10.022.

Trelease, R.B. (2008). Diffusion of innovations: smartphones and wireless anatomy learning resources. Anatomical Science Education, 1(6), 233-239. doi: 10.1002/ase.58.

Ward, P.J. (2011). Influence of study approaches on academic outcomes during pre-clinical medical education. Med Teach, 33(12), e651-662. doi: 10.3109/0142159X.2011.610843.

Ward, P.J., \& Walker, J.J. (2008). The influence of study methods and knowledge processing on academic success and long-term recall of anatomy learning by first-year veterinary students. Anatomical Science Education, 1(2), 68-74. doi: 10.1002/ase.12.

Weider, B. (2011). iPads could hinder teaching, professors say. Chronicle of Higher Education, 57, A22-A23. 